\title{
High prevalence of metabolic syndrome in an elderly Croatian population - a multicentre study
}

\author{
Daria Pašalić ${ }^{1}$, Slavica Dodig ${ }^{2}$, Naima Čorović ${ }^{3}$, Alica Pizent ${ }^{3}$, Jasna Jurasović ${ }^{3}$ and \\ Mladen Pavlović ${ }^{3, *}$ \\ 'Department of Chemistry and Biochemistry, School of Medicine, University of Zagreb, Zagreb, Croatia: \\ ${ }^{2}$ Reference Centre for Clinical Paediatric Allergy of the Ministry of Health and Social Welfare, Srebrnjak \\ Children's Hospital, Zagreb, Croatia: ${ }^{3}$ Institute for Medical Research and Occupational Health, \\ Ksaverska c. 2, HR-10000 Zagreb, Croatia
}

Submitted 18 December 2009: Accepted 21 0ctober 2010: First published online 8 December 2010

\begin{abstract}
Objective: To investigate the prevalence and characteristics of metabolic syndrome (MetS) in a healthy elderly Croatian population.

Design: Cross-sectional study consisting of a health check including anthropometric measures and food questionnaires as well as analysis of biochemical parameters related to MetS. The diagnostic criteria of the International Diabetes Federation (IDF) were used for diagnosis of MetS.

Setting: Four centres in continental (Virovitica and Zagreb) and Adriatic coast (Split and Omiš) regions of Croatia.

Subjects: Free-living elderly persons aged 70-90 years ( $n$ 320).

Results: Significantly lower MetS prevalence was found among participants from small urban centres compared with those from large urban centres $(59 \cdot 1 \% v$. $69.6 \% ; P=0.051)$. Participants without MetS consumed wine more frequently $(P=0 \cdot 05)$ than those with MetS. Compared with their peers with HDL cholesterol $(\mathrm{HDL}-\mathrm{C})<1.03 \mathrm{mmol} / \mathrm{l}$, more male participants with HDL-C $\geq 1.03 \mathrm{mmol} / 1 \mathrm{con}-$ sumed wine $(P=0 \cdot 04)$ or pelagic fish $(P=0 \cdot 03)$. The prevalence of participants with TAG $\geq 1.7 \mathrm{mmol} / 1$ was higher in wine non-consumers $(P=0.05)$ than in wine consumers. Multivariate analysis with age and gender as covariates showed a significant inverse association of wine consumption with total cholesterol $(P<0 \cdot 001)$, a positive association with HDL-C $(P<0 \cdot 001)$ and a marginally inverse association with TAG $(P=0 \cdot 06)$. In the male population, alkaline phosphatase and $\boldsymbol{\gamma}$-glutamyl transferase activities were higher in participants with MetS $(P<0 \cdot 05)$.

Conclusions: High MetS prevalence was observed in an elderly Croatian population. Data showed that moderate consumption of wine and/or pelagic fish has a protective role against MetS in the population studied.
\end{abstract}

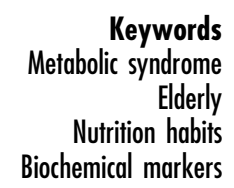

Metabolic syndrome (MetS) is a common metabolic disorder resulting from a cluster of interrelated abnormalities: obesity, hypertension, hyperglycaemia and dyslipidaemia $^{(1-3)}$. There are currently several definitions for MetS provided by various expert groups and organizations including WHO, the European Group for the Study of Insulin Resistance, the National Cholesterol Education Program - Third Adult Treatment Panel and the International Diabetes Federation (IDF) ${ }^{(4)}$. The aetiology of MetS includes obesity, which has been found to be responsible for the excess release of NEFA, cytokines and other pro-inflammatory factors, the development of insulin resistance and the development of hypertension and hyperlipidaemia ${ }^{(4)}$.
The number of persons with MetS has been increasing intensively over the past two decades. The consequence of such an increase is a global epidemic of obesity and diabetes $^{(5)}$. There is also a high risk of CVD, highlighting an urgent need for a strategy of prevention and treatment ${ }^{(6)}$.

Differences in lifestyle, nutrition and environmental conditions have an impact on health status, as well as on obesity, body fat distribution and predisposition for MetS. Obesity and higher body weight are strongly associated with sedentary lifestyle and lack of physical activity in the adult population of the European Union ${ }^{(7)}$. Comparison of published MetS prevalences in different populations is difficult because such estimates have been obtained using varying diagnostic criteria $^{(8)}$. Despite differences in the 
study designs and diagnostic criteria used, certain interferences can be found ${ }^{(4)}$. There is a wide variation with regard to prevalence in both sexes for the different populations studied, as well as for ethnic origin. MetS was also found to be highly age-dependent, with a higher prevalence in elderly people. MetS was significantly associated with age in populations from different Croatian island villages ${ }^{(9)}$. It is already known that nutritional habits have a significant impact on MetS ${ }^{(10)}$. The Mediterranean diet may reduce the incidence of $\mathrm{Met}^{(11)}$. It includes a high consumption of fruit, vegetables, legumes and whole grains, moderate alcohol intake, moderate to low consumption of meat and meat products, and high MUFA:SFA ratio.

The aim of the present study was to investigate the prevalence of MetS in relatively healthy elderly Croatian populations from four different centres. The influence of different lifestyle habits between continental and Mediterranean-Adriatic centres, as well as between rural and urban centres, was examined. We also estimated ageand sex-specific prevalence of MetS and analysed the association between different biochemical markers and MetS.

\section{Experimental methods}

\section{Study participants}

The cohort was established in the late 1960s from the Voter Registry $^{(12-14)}$. Initially (1969) the study was based on a random sample of the resident population, consisting of 4223 participants of both genders born between 1915 and 1934, from five communities representing two distinct climatic and cultural regions of Croatia. The cohort was re-examined in 1972 ( $n$ 3764), $1982(n$ 2415) and 2006 ( $n$ 385) based on a registry of vital records. Continental Croatia was represented by two centres: the Virovitica municipality (mainly rural region, situated in the vicinity of the Hungarian border) and the City of Zagreb (Western District and Centre). The coastal region also included two centres: Omiš municipality and the City of Split. The Omiš municipality included a small proportion of an urban population (25\%) and the rest were from the surrounding rural and suburban area. The study centres were not directly affected by the 1991-1995 war in Croatia and the sample was selected as follows. During 2005, 2415 persons who had participated in the study in 1982 were identified, based on verification from: postal address in the Voter Registry, data on residential status, community health services, the Register of Deaths, nursing homes, and a short postal questionnaire or phone contact. In 2006, 907 survivors who had not moved away were invited to take part in the study. Of these, 317 could not be traced (they did not respond the invitation), seventy-seven refused to participate, and 128 were immobile, sick or lived in a nursing home and were consequently excluded from the study. The final sample included in the 2006 cross-sectional survey consisted of 385 volunteers aged more than 70 years.
All participants were free-living, able to take care of themselves and to manage their everyday activities (inclusion criteria: non-institutionalized mobile residents, nonfebrile at the time of medical check-up, cooperative for spirometry and with positive attitude towards participation in the study). Exclusion of sixty-five participants with missing anthropometric or questionnaire data, low blood sample volume for biochemical analyses or infectious and/or chronic liver diseases left a study population of 320 elderly persons among whom prevalence of MetS was investigated. The cohort was divided into continental $v$. coastal, rural $v$. urban and third (70-75 years) $v$. fourth (76-90 years) age subgroups.

The study was performed in accordance with the ethical principles of the Helsinki Declaration and was approved by a competent ethics committee. Informed consent was obtained from each examinee before inclusion in the study. Nurses and physicians were qualified and appropriately trained.

Tests were performed between 07.00 and 12.00 hours. The clinical interview comprised questions based on verified and coded history of chronic diseases classified by the International Classification of Diseases, IX Revision. The study also comprised a questionnaire related to eating habits: lard, olive oil, hard cheese, wine, spirits, pelagic fish (anchovy and/or mackerel and/or tuna) and freshwater fish (carp and/or catfish and/or trout). Regarding stated eating habits, participants were categorized into two subgroups. Those who reported daily consumption of lard, olive oil, spirits and wine and monthly (or more frequent) consumption of cheese and fish were assumed as one subgroup. The other subgroup consisted of participants who stated that they do not consume those foodstuffs at all or consume them rarely. Alcohol intake was measured by standard measures ( 1 drink $=200 \mathrm{ml}$ wine or $30 \mathrm{ml}$ spirits) and moderate drinking was defined as up to 3 drinks/ $\mathrm{d}^{(15)}$. Social circumstances, income, marital status and psychological instruments, including brief assessment of cognitive function, were also included in the questionnaire.

Arterial blood pressure measurements were obtained on two occasions in sitting position after 10-20 min rest, using a desk-type mercury sphygmomanometer (Reister, Jungingen, Germany).

Medical examination included anthropometric measurements, body height, waist circumference (WC) and body mass (portable field survey scale Korona 3516701; Niko Weiss Best, Korona, Germany) as well as BMI. BMI was calculated according to the formula: [mass (kg)]/ [body height $(\mathrm{m})]^{2}$. Height, weight and WC were measured according to the International Biological Programme Protocol.

\section{Diagnosis of metabolic syndrome}

MetS was diagnosed on the basis of anthropometric measurements, biochemical parameters (fasting glucose, 
TAG and HDL-cholesterol (HDL-C)) and arterial blood pressure. The IDF criteria for diagnosis of MetS were used. According to the IDF criteria, MetS was diagnosed if WC was $\geq 94 \mathrm{~cm}$ for males or $\geq 80 \mathrm{~cm}$ for females, plus any two of the following: fasting glucose $\geq 5.6 \mathrm{mmol} / \mathrm{l}$ (or previously diagnosed diabetes mellitus and antidiabetic therapy), TAG $\geq 1.7 \mathrm{mmol} / 1$, HDL-C $<1.03 \mathrm{mmol} / 1$ for males or $<1.29 \mathrm{mmol} / 1$ for females, and blood pressure $\geq 130 / 85 \mathrm{mmHg}$

\section{Biochemical analyses}

Blood samples were drawn from an antecubital vein after an overnight fast. Blood samples were centrifuged, divided into $1 \mathrm{ml}$ aliquots and stored frozen. Glucose was measured using the enzymatic hexokinase method and the catalytic activity of alkaline phosphatase (ALP) and $\gamma$-glutamyl transferase (GGT) by standardized methods. Analyses were performed on an Olympus AU400 selective autoanalyser (Olympus, Tokyo, Japan) using reagents from the same manufacturer (Olympus, Hamburg, Germany).

Lipoprotein parameters were measured on a Roche COBAS MIRA autoanalyser using enzymatic methods with reagents from Boehringer-Mannheim Diagnostics and Hoffmann-La Roche (Roche Diagnostics, Mannheim, Germany). LDL cholesterol (LDL-C) was calculated according to the Friedewald formula. To avoid participants with potential infectious diseases and also with liver diseases, we excluded those with C-reactive protein $>10 \mathrm{mg} / \mathrm{l}$, ALP $>100 \mathrm{U} / 1$ and GGT $>60 \mathrm{U} / \mathrm{l}$.

\section{Statistical analysis}

Statistical analyses were performed with the STATISTICA 7 for Windows statistical software package (StatSoft, Inc., Tulsa, OK, USA). MetS group frequencies were calculated by counting. Categorical variables were compared using Pearson's $\chi^{2}$ test. Binary logistic regression was used to assess the association between diet and MetS, with adjustment for centres. Continuous variables are expressed as mean and standard deviation or standard error. Group comparisons of continuous variables were performed by Student's $t$ test. Multivariate analysis (MANOVA) with age and gender as covariates was used for testing the effects of dietary habits on continuous variables. The level of significance was set at $0 \cdot 05$.

\section{Results}

Using the IDF definition, MetS was identified in 206 (64.4\%) out of 320 elderly participants (aged $70-90$ years) from four centres in continental and coastal Croatian regions. Frequency of MetS did not differ between the centres (Table 1). After pooling the two continental centres (Zagreb and Virovitica) and the two Adriatic coast centres (Split and Omiš), comparison of MetS frequencies between the continental region and the Adriatic coast did not show
Table 1 The frequency of metabolic syndrome in elderly participants (aged 70-90 years, $n$ 320) from four centres in continental and coastal Croatia

\begin{tabular}{|c|c|c|c|c|}
\hline \multirow[b]{2}{*}{ Centre } & \multicolumn{2}{|c|}{$\begin{array}{c}\text { MetS }(-) \\
(n 114)\end{array}$} & \multicolumn{2}{|c|}{$\begin{array}{c}\text { MetS }(+) \\
(n 206)\end{array}$} \\
\hline & $n$ & $\%$ & $n$ & $\%$ \\
\hline Zagreb & 37 & $31 \cdot 3$ & 82 & 68.9 \\
\hline Virovitica & 25 & $40 \cdot 3$ & 37 & $59 \cdot 7$ \\
\hline Omiš & 40 & $41 \cdot 2$ & 57 & $58 \cdot 8$ \\
\hline Split & 12 & $28 \cdot 6$ & 30 & $71 \cdot 4$ \\
\hline
\end{tabular}

MetS (-), without metabolic syndrome; MetS $(+)$, with metabolic syndrome. No significant difference in MetS prevalence by study centre: $P=0 \cdot 272$.

Table 2 The frequency of metabolic syndrome in elderly Croatian participants (aged 70-90 years, $n$ 320), according to large and small urban centres

\begin{tabular}{lccrrr}
\hline & \multicolumn{2}{c}{$\begin{array}{c}\text { MetS }(-) \\
(n 114)\end{array}$} & & \multicolumn{2}{c}{$\begin{array}{c}\text { MetS }(+) \\
(n \text { 206) }\end{array}$} \\
\cline { 2 - 3 } \cline { 5 - 6 } Centre & $n$ & & & $n$ & $\%$ \\
\hline Larget & 49 & $30 \cdot 4$ & & 112 & $69 \cdot 6$ \\
Small & 65 & 40.9 & & 94 & $59 \cdot 1$ \\
\hline
\end{tabular}

MetS (-), without metabolic syndrome; MetS $(+)$, with metabolic syndrome. Significant difference in MetS prevalence by size of urban centre: $P=0.05$. †Zagreb and Split.

‡Omiš and Virovitica.

any significant difference. However, when we compared the large centres (Zagreb and Split) with the small centres (Virovitica and Omiš) there was a significant difference in prevalence of MetS (Table 2). Significantly lower MetS prevalence was found among participants from small urban centres in comparison to those from large urban centres $(59 \cdot 1 \% v \cdot 69 \cdot 6 \% ; P=0 \cdot 051)$. No gender difference in MetS frequencies was found in the entire study group $(P=0 \cdot 47)$, between participants from the continental centres $(P=0 \cdot 20)$ or between those from the Adriatic coast $(P=0 \cdot 68)$. The results were similar when the participants from the two large urban centres $(P=0 \cdot 17)$ or the small urban centres $(P=0 \cdot 75)$ were compared according to gender. Moreover, when participants were classified by age into two groups (70-75 years $v$. 76-90 years), no significant differences in MetS prevalence were found between the groups $(P=0 \cdot 57)$.

Differences were observed in nutritional habits between participants from the continental centres and the Adriatic centres, as well as between participants from the large and small urban centres (Table 3). Participants from the Adriatic coast had higher consumption of olive oil, pelagic fish, hard cheese and wine, whereas the dietary pattern among those from the continental centres included higher consumption of lard, freshwater fish and spirits. Participants from the large urban centres consumed more olive oil and hard cheese, whereas those from the small urban centres consumed more lard, freshwater fish, spirits and wine. However, when the nutritional habits of the participants were compared with 
Table 3 Comparison of nutritional habits in elderly Croatian participants (aged 70-90 years, $n$ 320), according to continental and coastal centres, and large and small urban centres

\begin{tabular}{|c|c|c|c|c|}
\hline Nutrient & Continentalt & Coastalł & Large & Small $\|$ \\
\hline Lard $\boldsymbol{\top}$ & $45 \cdot 2$ & $17 \cdot 9^{\star \star \star}$ & $25 \cdot 5$ & $41 \cdot 6^{\star \star}$ \\
\hline Olive oil & $44 \cdot 6$ & $94 \cdot 8^{\star \star \star}$ & $71 \cdot 3$ & $61 \cdot 3^{N S}$ \\
\hline Hard cheesett & $57 \cdot 1$ & $68 \cdot 9^{*}$ & $71 \cdot 6$ & $52 \cdot 9^{\star *}$ \\
\hline Freshwater fishtt & $41 \cdot 5$ & $28 \cdot 0^{\star}$ & $27 \cdot 1$ & $44 \cdot 4^{\star \star}$ \\
\hline Pelagic fishtt & $61 \cdot 4$ & $85 \cdot 2^{\star \star \star}$ & $72 \cdot 4$ & $71 \cdot 0^{\mathrm{NS}}$ \\
\hline Spirits & $14 \cdot 0$ & $0 \cdot 7^{\star \star \star}$ & $3 \cdot 8$ & $13 \cdot 0^{\star *}$ \\
\hline Wine & $37 \cdot 3$ & $57 \cdot 0^{\star *}$ & $38 \cdot 6$ & $53 \cdot 2^{\star *}$ \\
\hline
\end{tabular}

Data represent the percentages of participants who reported $\uparrow$ daily (for lard, olive oil, spirits and wine) or ttmonthly or more frequent (for cheese and fish) intake of the nutrient.

Significance of the difference in the percentages of participants consuming the nutrient in continental $v$. coastal centres or large $v$. small urban centres: ${ }^{\star} P \leq 0.05,{ }^{\star \star} P<0.01,{ }^{\star \star *} P<0.001$.

+Zagreb and Virovitica.

$\ddagger$ Split and Omiš.

$\S Z a g r e b$ and Split.

IIOmiš and Virovitica.

Table 4 Comparison of nutritional habits in elderly Croatian participants (aged 70-90 years, $n$ 320) from different centres, according to the presence of metabolic syndrome

\begin{tabular}{lcc}
\hline Nutrient & MetS $(-)$ & MetS $(+)$ \\
\hline Lard $t$ & $37 \cdot 5$ & $31 \cdot 5^{\mathrm{NS}}$ \\
Olive oilt & $67 \cdot 0$ & $65 \cdot 7^{\mathrm{NS}}$ \\
Hard cheese & $57 \cdot 1$ & $64 \cdot 9^{\mathrm{NS}}$ \\
Freshwater fish $\ddagger$ & $33 \cdot 3$ & $36 \cdot 6^{\mathrm{NS}}$ \\
Pelagic fish $\ddagger$ & $71 \cdot 4$ & $72 \cdot 4^{\mathrm{NS}}$ \\
Spiritst & $8 \cdot 8$ & $7 \cdot 8^{\mathrm{NS}}$ \\
Winet & $52 \cdot 6$ & $41 \cdot 5^{\star}$ \\
\hline
\end{tabular}

MetS (-), without metabolic syndrome; MetS $(+)$, with metabolic syndrome. Data represent the percentages of participants who reported tdaily (for lard, olive oil, spirits and wine) or fmonthly or more frequent (for cheese and fish) intake of the nutrient.

Significance of the difference in the percentages of participants with MetS $v$. without MetS consuming the nutrient: ${ }^{*} P \leq 0 \cdot 05$.

regard to the presence or absence of MetS (Table 4), a statistically significant difference was found only for wine $(P=0 \cdot 05)$; that is, consumption of wine was less frequent among participants with MetS. Binary logistic regression analysis, with adjustments for centres (four different centres), showed similar results (data not presented).

Table 5 shows the anthropometric and biochemical parameters in the groups of participants with or without MetS diagnosed, the differences between the groups being tested with Student's $t$ test. The statistically significant differences between participants with and without MetS which were observed for BMI, WC, glucose, TAG and HDL-C confirm correct use of the diagnostic criteria for MetS. There were no significant differences for age, total cholesterol and LDL-C. In the male population, ALP and GGT activities were significantly higher in participants with MetS than in those without MetS. Relative consumption frequencies of lard, hard cheese, olive oil, pelagic fish and wine, with regard to cut-off levels for the biochemical components of MetS, are shown in Table 6. Compared with their peers with HDL-C $<1.03 \mathrm{mmol} / \mathrm{l}$, more male participants with HDL-C $\geq 1.03 \mathrm{mmol} / \mathrm{l}$ consumed wine $(P=0.04)$ or pelagic fish $(P=0.03)$. The prevalence of participants with TAG $\geq 1.7 \mathrm{mmol} / \mathrm{l}$ was significantly higher in wine non-consumers $(P=0 \cdot 05)$ than in wine consumers. There were also statistically significant differences in wine consumption according to gender (60.7\% of men and $39.3 \%$ of women; $P<0 \cdot 001$ ). Table 7 presents multivariate analysis of the biochemical parameters according to wine consumption, with age and gender as covariates. Results showed a significant inverse association of wine consumption with total cholesterol $(P<0 \cdot 001)$, a significant positive association with HDL-C $(P<0 \cdot 001)$ and a marginally inverse association with TAG $(P=0 \cdot 06)$.

\section{Discussion}

In most countries worldwide between $20 \%$ and $30 \%$ of the adult population can be characterized as having MetS, although in certain populations or population segments MetS prevalence is even higher. Populations in which young adults predominate have lower MetS prevalence, but MetS prevalence increases with increasing affluence and ageing of the population ${ }^{(16)}$. Our study was conducted among a relatively healthy, free-living elderly Croatian population with age more than 70 years. The prevalence of MetS in this population ranged between $60 \%$ and $70 \%$ according to the IDF diagnostic criteria. Epidemiological data on MetS prevalence in elderly populations are rare. In an earlier study of regional prevalence of MetS in 9070 Croatian subjects ${ }^{(17)}$ the prevalence was found to be $15 \cdot 2 \%$ for males and $22.5 \%$ for females. However, in that study the diagnostic criteria for MetS differed from the IDF criteria (WC $\geq 102 \mathrm{~cm}$ for males and $\geq 88 \mathrm{~cm}$ for females, and at least two of the following: arterial blood pressure $\geq 140 / 90 \mathrm{~mm} \mathrm{Hg}$, selfreported elevated blood lipids and self-reported elevated blood sugar). Increased prevalence of MetS in elderly populations was also observed in several European population studies. Estimated MetS prevalence (according to IDF criteria) in the population-based KORA Survey 2000 (age group 55-74 years) was 46\% for women and $57 \%$ for men ${ }^{(18)}$. The MetS-Greece Multicentre Study showed a $14 \cdot 7$-fold increased risk for having MetS in the age group $>70$ years old ${ }^{(19)}$.

As we took into account populations from four different Croatian centres (two continental: Zagreb and Virovitica; two coastal: Split and Omiš) it was interesting to analyse the differences between them. Regional differences in the Croatian population have been observed before, particularly regarding risk factors for $\mathrm{CHD}^{(20)}$. Hospitalized patients in the continental regions had higher prevalence of hypertension and decreased HDL-C ${ }^{(21)}$. The present results did not show any significant differences in the frequency of MetS between the Adriatic coastal centres and the continental centres. However, we observed 
Table 5 Anthropometric and biochemical parameters, and the differences between groups with or without metabolic syndrome, in elderly Croatian participants (aged 70-90 years, $n$ 320) from different centres

\begin{tabular}{|c|c|c|c|c|c|c|c|c|}
\hline \multirow[b]{2}{*}{ Parameter } & & \multicolumn{3}{|c|}{ MetS (-) (n 114) } & \multicolumn{3}{|c|}{ MetS $(+)(n 206)$} & \multirow[b]{2}{*}{$P$} \\
\hline & & Mean & SD & $\mathrm{SE}$ & Mean & SD & SE & \\
\hline \multirow[t]{3}{*}{ BMI $\left(\mathrm{kg} / \mathrm{m}^{2}\right)$} & $\mathrm{T}$ & $26 \cdot 6$ & $3 \cdot 8$ & 0.37 & $29 \cdot 7$ & 3.5 & 0.25 & 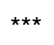 \\
\hline & $\mathrm{M}$ & $26 \cdot 5$ & $3 \cdot 6$ & 0.51 & $29 \cdot 0$ & $2 \cdot 9$ & 0.31 & $* \star *$ \\
\hline & $\mathrm{F}$ & $26 \cdot 7$ & $4 \cdot 0$ & 0.52 & $30 \cdot 2$ & $3 \cdot 8$ & 0.35 & $\star \star \star *$ \\
\hline \multirow[t]{3}{*}{ WC $(\mathrm{cm})$} & $\mathrm{T}$ & $94 \cdot 6$ & $16 \cdot 7$ & 1.53 & $102 \cdot 5$ & $10 \cdot 0$ & 0.66 & 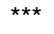 \\
\hline & $\mathrm{M}$ & $102 \cdot 9$ & $17 \cdot 8$ & $2 \cdot 44$ & $116 \cdot 1$ & $9 \cdot 3$ & 0.93 & 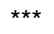 \\
\hline & $\mathrm{F}$ & $87 \cdot 0$ & $12 \cdot 4$ & $1 \cdot 62$ & $100 \cdot 5$ & $10 \cdot 1$ & $0 \cdot 88$ & 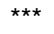 \\
\hline \multirow[t]{3}{*}{ Age (years) } & $\mathrm{T}$ & $78 \cdot 7$ & $4 \cdot 6$ & 0.44 & $77 \cdot 9$ & $4 \cdot 4$ & $0 \cdot 31$ & NS \\
\hline & $\mathrm{M}$ & $79 \cdot 1$ & $4 \cdot 3$ & 0.61 & 78.6 & $4 \cdot 7$ & 0.51 & NS \\
\hline & $\mathrm{F}$ & 78.5 & $4 \cdot 8$ & 0.63 & $77 \cdot 4$ & $4 \cdot 1$ & 0.38 & NS \\
\hline \multirow{3}{*}{ Glucose $(\mathrm{mmol} / \mathrm{l})$} & $\mathrm{T}$ & $5 \cdot 1$ & $1 \cdot 4$ & 0.12 & 6.9 & $2 \cdot 7$ & 0.20 & 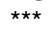 \\
\hline & $\mathrm{M}$ & $5 \cdot 2$ & $1 \cdot 4$ & 0.22 & $7 \cdot 1$ & $2 \cdot 5$ & 0.29 & 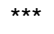 \\
\hline & $\mathrm{F}$ & $5 \cdot 1$ & 0.8 & 0.12 & $6 \cdot 9$ & $2 \cdot 8$ & 0.28 & 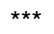 \\
\hline \multirow{3}{*}{ TAG (mmol/l) } & $\mathrm{T}$ & $1 \cdot 2$ & 0.44 & 0.04 & $2 \cdot 0$ & $1 \cdot 1$ & 0.07 & $\star \star \star *$ \\
\hline & $M$ & $1 \cdot 2$ & 0.45 & 0.06 & $1 \cdot 9$ & $1 \cdot 3$ & $0 \cdot 13$ & $\star \star \star *$ \\
\hline & $\mathrm{F}$ & $1 \cdot 2$ & 0.44 & 0.06 & $2 \cdot 0$ & 0.8 & 0.08 & $\star \star \star *$ \\
\hline \multirow[t]{3}{*}{ Total cholesterol (mmol/l) } & $\mathrm{T}$ & $5 \cdot 4$ & 0.99 & 0.09 & $5 \cdot 4$ & $1 \cdot 2$ & 0.09 & NS \\
\hline & $M$ & $5 \cdot 1$ & 0.83 & 0.11 & $5 \cdot 1$ & $1 . \overline{2}$ & $0 \cdot 12$ & NS \\
\hline & $\mathrm{F}$ & $5 \cdot 7$ & $1 \cdot 04$ & 0.13 & $5 \cdot 7$ & $1 \cdot 2$ & $0 \cdot 11$ & NS \\
\hline \multirow[t]{3}{*}{ HDL-C (mmol/l) } & $\mathrm{T}$ & $1 \cdot 5$ & 0.42 & 0.04 & $1 \cdot 1$ & 0.3 & 0.02 & $* \star *$ \\
\hline & $M$ & $1 \cdot 3$ & 0.46 & 0.06 & $1 \cdot 0$ & 0.3 & 0.03 & $\star \star \star *$ \\
\hline & $\mathrm{F}$ & $1 \cdot 6$ & 0.35 & 0.04 & $1 \cdot 2$ & 0.4 & 0.03 & $* \star *$ \\
\hline \multirow{3}{*}{ LDL-C (mmol/l) } & $\mathrm{T}$ & $3 \cdot 4$ & 0.99 & 0.09 & $3 \cdot 4$ & $1 \cdot 1$ & 0.08 & NS \\
\hline & $M$ & $3 \cdot 2$ & 0.92 & $0 \cdot 13$ & $3 \cdot 3$ & $1 \cdot 2$ & $0 \cdot 13$ & NS \\
\hline & $\mathrm{F}$ & $3 \cdot 6$ & 1.02 & $0 \cdot 13$ & $3 \cdot 6$ & $1 \cdot \overline{0}$ & 0.09 & NS \\
\hline \multirow{3}{*}{ ALP (U/I) } & $\mathrm{T}$ & $46 \cdot 0$ & 14.9 & 1.50 & $46 \cdot 7$ & $16 \cdot 7$ & $2 \cdot 50$ & NS \\
\hline & $\mathrm{M}$ & $41 \cdot 7$ & $12 \cdot 0$ & 1.90 & $49 \cdot 3$ & $15 \cdot 9$ & $5 \cdot 10$ & * \\
\hline & $\mathrm{F}$ & $49 \cdot 6$ & $16 \cdot 5$ & $2 \cdot 26$ & $50 \cdot 1$ & $17 \cdot 4$ & $2 \cdot 13$ & NS \\
\hline \multirow[t]{3}{*}{ GGT (U/I) } & $\mathrm{T}$ & $22 \cdot 8$ & $10 \cdot 5$ & $2 \cdot 80$ & $26 \cdot 7$ & $13 \cdot 2$ & 3.60 & * \\
\hline & $M$ & $26 \cdot 3$ & $12 \cdot 5$ & 4.00 & 31.9 & $14 \cdot 0$ & $7 \cdot 60$ & * \\
\hline & $\mathrm{F}$ & $20 \cdot 1$ & $7 \cdot 9$ & 4.00 & $22 \cdot 7$ & $11 \cdot 1$ & $1 \cdot 80$ & NS \\
\hline
\end{tabular}

MetS (-), without metabolic syndrome; MetS (+), with metabolic syndrome; WC, waist circumference; HDL-C, HDL cholesterol; LDL-C, LDL cholesterol; ALP, alkaline phosphatase; GGT, $\gamma$-glutamyl transferase; T, total; M, male; F, female.

Mean value was significantly different in participants with MetS $v$. without MetS: ${ }^{\star} P \leq 0 \cdot 05,{ }^{\star \star *} P<0 \cdot 001$.

Table 6 Relative consumption frequencies of lard, cheese, olive oil, pelagic fish and wine with regard to cut-off levels for biochemical components of the metabolic syndrome in elderly Croatian participants (aged 70-90 years, $n$ 320) from different centres

\begin{tabular}{|c|c|c|c|c|c|c|c|c|c|c|}
\hline \multirow[b]{2}{*}{ Parameter } & \multicolumn{2}{|c|}{ Lardt } & \multicolumn{2}{|c|}{ Olive oilt } & \multicolumn{2}{|c|}{ Hard cheeseł } & \multicolumn{2}{|c|}{ Pelagic fish $\ddagger$} & \multicolumn{2}{|c|}{ Winet } \\
\hline & No & Yes & No & Yes & No & Yes & No & Yes & No & Yes \\
\hline \multicolumn{11}{|l|}{ Glucose (mmol/l) } \\
\hline$<5 \cdot 6$ & 54.5 & $62 \cdot 2$ & $53 \cdot 8$ & 61.5 & $58 \cdot 0$ & $55 \cdot 4$ & $60 \cdot 9$ & $55 \cdot 1$ & $53 \cdot 4$ & $60 \cdot 7$ \\
\hline$\geq 5 \cdot 6$ & $45 \cdot 5$ & $37 \cdot 8$ & $46 \cdot 2$ & 38.5 & $42 \cdot 0$ & $44 \cdot 6$ & $39 \cdot 1$ & $44 \cdot 9$ & $46 \cdot 6$ & $39 \cdot 3$ \\
\hline$P$ & \multicolumn{2}{|c|}{0.30} & \multicolumn{2}{|c|}{0.20} & \multicolumn{2}{|c|}{0.68} & \multicolumn{2}{|c|}{0.41} & \multicolumn{2}{|c|}{0.23} \\
\hline \multicolumn{11}{|l|}{ TAG $(\mathrm{mmol} / \mathrm{l})$} \\
\hline$<1 \cdot 7$ & $56 \cdot 0$ & $57 \cdot 9$ & $60 \cdot 3$ & $66 \cdot 0$ & $65 \cdot 5$ & $55 \cdot 9$ & $59 \cdot 1$ & $59 \cdot 5$ & $54 \cdot 6$ & $65 \cdot 5$ \\
\hline$\geq 1 \cdot 7$ & $44 \cdot 0$ & $42 \cdot 1$ & $39 \cdot 7$ & $34 \cdot 0$ & 34.5 & $44 \cdot 1$ & 40.9 & $40 \cdot 5$ & $45 \cdot 5$ & 34.5 \\
\hline$P$ & \multicolumn{2}{|c|}{0.09} & \multicolumn{2}{|c|}{0.69} & \multicolumn{2}{|c|}{0.09} & \multicolumn{2}{|c|}{0.95} & \multicolumn{2}{|c|}{0.05} \\
\hline \multicolumn{11}{|l|}{$\mathrm{HDL}-\mathrm{C}(\mathrm{mmol} / \mathrm{l})$} \\
\hline$<1.03$ (male, $n$ 141) & $40 \cdot 9$ & $53 \cdot 5$ & $40 \cdot 0$ & $51 \cdot 1$ & $52 \cdot 5$ & $40 \cdot 8$ & $61 \cdot 3$ & $38 \cdot 7$ & $60 \cdot 4$ & $35 \cdot 2$ \\
\hline$\geq 1.03$ & $59 \cdot 1$ & $46 \cdot 5$ & $60 \cdot 0$ & 48.9 & $47 \cdot 5$ & $59 \cdot 2$ & $38 \cdot 7$ & $61 \cdot 3$ & $39 \cdot 6$ & $64 \cdot 8$ \\
\hline$P$ & \multicolumn{2}{|c|}{0.26} & \multicolumn{2}{|c|}{$0 \cdot 14$} & \multicolumn{2}{|c|}{0.21} & \multicolumn{2}{|c|}{0.03} & \multicolumn{2}{|c|}{0.04} \\
\hline$<1 \cdot 29$ (female, $n$ 179) & $54 \cdot 8$ & $58 \cdot 7$ & $50 \cdot 9$ & $50 \cdot 8$ & $53 \cdot 2$ & $53 \cdot 1$ & $58 \cdot 9$ & $51 \cdot 2$ & $55 \cdot 8$ & $49 \cdot 1$ \\
\hline$\geq 1 \cdot 29$ & $45 \cdot 2$ & $41 \cdot 3$ & $49 \cdot 1$ & $49 \cdot 2$ & $46 \cdot 8$ & 46.9 & $41 \cdot 1$ & $48 \cdot 8$ & $44 \cdot 2$ & $50 \cdot 9$ \\
\hline$P$ & \multicolumn{2}{|c|}{0.62} & \multicolumn{2}{|c|}{0.32} & \multicolumn{2}{|c|}{0.99} & \multicolumn{2}{|c|}{0.34} & \multicolumn{2}{|c|}{0.40} \\
\hline
\end{tabular}

HDL-C, HDL cholesterol.

Data represent the percentages of participants who declined (no) or reported (yes) tdaily (for lard, olive oil and wine) or łmonthly or more frequent (for cheese and fish) intake of the nutrient.

significantly higher MetS prevalence in the large urban centres compared with the small centres, with the emphasis on rural lifestyle habits. This difference might be attributable to diet. The HALE project on elderly European men and women showed that Mediterranean diet, moderate alcohol consumption, moderate to high 
Table 7 The influence of wine consumption on relevant biochemical parameters in elderly Croatian participants (aged 70-90 years, $n$ 320) from different centres

\begin{tabular}{|c|c|c|c|c|c|c|c|}
\hline \multirow[b]{2}{*}{ Parameter } & \multicolumn{3}{|c|}{ Wine (no) } & \multicolumn{3}{|c|}{ Wine (yes) } & \multirow[b]{2}{*}{$P$ (MANOVAt) } \\
\hline & Mean & SD & SE & Mean & SD & SE & \\
\hline Glucose $(\mathrm{mmol} / \mathrm{l})$ & $6 \cdot 47$ & $2 \cdot 59$ & $0 \cdot 21$ & $6 \cdot 13$ & $2 \cdot 19$ & $0 \cdot 20$ & 0.45 \\
\hline TAG $(\mathrm{mmol} / \mathrm{l})$ & $1 \cdot 76$ & 0.97 & 0.07 & 1.65 & 0.94 & 0.08 & 0.06 \\
\hline Total cholesterol $(\mathrm{mmol} / \mathrm{l})$ & $5 \cdot 47$ & $1 \cdot 16$ & 0.09 & $5 \cdot 38$ & $1 \cdot 13$ & 0.09 & $<0.01$ \\
\hline HDL-C (mmol/l) & $1 \cdot 21$ & 0.41 & 0.03 & $1 \cdot 27$ & 0.41 & 0.03 & $<0.01$ \\
\hline LDL-C (mmol/l) & $3 \cdot 43$ & $1 \cdot 15$ & 0.09 & $3 \cdot 36$ & 0.99 & 0.08 & 0.01 \\
\hline
\end{tabular}

HDL-C, HDL cholesterol; LDL-C, LDL cholesterol.

tMultivariate analysis; covariates: age and gender.

physical activity levels and non-smoking were associated with lower mortality rates from all causes, CHD, CVD, cancer and other causes during a 10-year follow-up period $^{(22)}$. An optimal diet for the prevention of weight gain, obesity, MetS and type 2 diabetes is reported to be a fat-reduced diet without any industrially produced trans fatty acids, fibre-rich, high in low-energy-density carbohydrates (fruit, vegetables and whole-grain products) and with a restricted intake of energy-containing drinks ${ }^{(23)}$. FFQ data previously showed significant differences in nutritional habits, including greater amounts of pelagic fish (rich in PUFA), olive oil (rich in MUFA and polyphenols) and wine (rich in polyphenols), in subjects of Mediterranean origin ${ }^{(24)}$. Although no data are available, it is generally known that nutritional habits in the Mediterranean have changed greatly over the past two decades, mainly because of socio-economic factors. For example, consumption of poor-quality carbohydrates and meat has increased in the Mediterranean region, especially in the urban areas. Such data were confirmed by investigations on the prevalence of chronic diseases, such as obesity, diabetes and cardiovascular disorders in the southern Mediterranean (African) countries ${ }^{(25)}$. Data reported from this region showed that there has been a shift in dietary habits from a traditional Mediterranean diet to industrial food, including high consumption of SFA and refined carbohydrates, low fibre consumption as well as sedentary behaviour ${ }^{(25)}$. A multicentre study of the Mediterranean Group for the Study of Diabetes showed that MetS is not related to the Mediterranean type of diet and its prevalence varied greatly among five Mediterranean countries ${ }^{(26)}$. The prevalence of MetS in an isolated population on the Croatian island of Hvar was significantly high in spite of adherence to a relatively traditional lifestyle pattern, together with a Mediterranean diet and rural habitat ${ }^{(27)}$.

This exaggerated rate and risks for CVD and diabetes could be attributed to increasing urbanization with effective changes in lifestyles. Higher prevalence of MetS in urban rather than rural areas has been observed for several different populations ${ }^{(28-30)}$. The reasons for the difference between urban and rural prevalences of MetS and other chronic diseases lie in the characteristics of urbanization $^{(31)}$. Urbanization includes access to energydense industrialized foods, technological changes in both work and transportation, and reduced physical activities in the workplace and at leisure time ${ }^{(28)}$. Our questionnaire data showed higher prevalences of different kinds of daily physical activity in participants from the rural area. Persons who live in a rural area practise livestock breeding, horticulture, fishing, etc. Epidemiological studies suggest that regular physical activity prevents MetS, type 2 diabetes, CVD and premature mortality ${ }^{(32)}$. In a study among employees of a large manufacturing company, men with MetS who reported higher levels of anxiety, anger and work stress had higher blood pressure than men without MetS, who reported lower levels of these mental health indicators ${ }^{(33)}$.

A number of studies have focused on the relationship between alcohol consumption and prevalence of MetS. Nutritional habits of our study participants with and without MetS did not differ significantly apart from the consumption of wine. The results indicated that wine might have a protective effect against MetS. A trend for lower MetS prevalence with alcohol consumption was observed in a Mediterranean Greek population study, which also showed that wine consumption was associated with a slightly better effect than beer or spirits consumption on the prevalence of $\mathrm{CVD}^{(31)}$. A Quebec cardiovascular study showed that moderate daily alcohol consumption has cardioprotective properties, especially in persons with a deteriorated risk profile, such as those with MetS ${ }^{(34)}$. However alcohol consumption might show opposite effects on manifestation of MetS. This depends primarily on the amounts and types of alcohol consumed $^{(35)}$. Moderate alcohol consumption is associated with a decreased incidence of MetS and beneficial effects on plasma lipid levels (increase in plasma HDL-C levels), WC and fasting plasma glucose ${ }^{(36)}$. Moderate wine consumption in our study (mean wine intake 0.33 (95\% CI $0 \cdot 15,0 \cdot 55) \mathrm{l} / \mathrm{d}$; i.e. $1 \cdot 65$ standard drinks daily) confirmed a beneficial effect on TAG, total cholesterol, HDL-C and LDL-C concentrations in men. The relationship between alcohol consumption and incidence of MetS is more pronounced among red wine consumers because the polyphenols contained in red wine increase the activity of 
endothelial nitric oxide synthase that plays a key role in the pathogenesis of MetS as well as in the transport of HDL molecules ${ }^{(37)}$.

Non-alcoholic fatty liver disease may be considered an additional feature of $\mathrm{MetS}^{(38)}$. The increasing prevalences of obesity, diabetes, dyslipidaemia and hypertension, characteristics of MetS, put a very large population at risk of forthcoming liver failure ${ }^{(39)}$. People with non-alcoholic fatty liver disease typically have elevated circulating concentrations of markers of liver injury, including aspartate aminotransferase, alanine aminotransferase, GGT and $\mathrm{ALP}^{(40)}$. We noticed slightly higher activity of ALP and GGT in participants with MetS, although only in men, who consume more wine than women (Table 5). Thus we cannot conclude that increased markers of liver injury are due only to MetS, and thereby the consumption of wine might have opposite effects on a person's health. Several population studies have shown the influence of obesity and alcohol consumption on increased serum GGT activity ${ }^{(41)}$. Obesity and moderate drinking seem to have synergistic effect on increasing the risk of liver injury ${ }^{(42)}$. It is known that alcohol induces hepatic microsomal production of GGT, or it may cause the leakage of liver enzymes, including $\mathrm{GGT}^{(43)}$. Although ALP is not primary indicator of liver injury, taking into account increased GGT in the current population of older and relatively healthy people (and the known relationship between ALP and GGT), slightly increased ALP in men with MetS might be due to moderate liver injury.

In the present study there was evidence that the prevalence of men with $\mathrm{HDL}-\mathrm{C} \geq 1.03 \mathrm{mmol} / \mathrm{l}$ (cut-off for MetS) was higher in those who consumed pelagic fish. It is well known that pelagic fish are rich in PUFA ${ }^{(44)} \cdot n-3$ PUFA have been shown to reduce total cholesterol and LDL-C, and to increase HDL- $\mathrm{C}^{(45)}$. However, the beneficial effects of $n-3$ fatty acids in lowering TAG levels and increasing HDL-C levels are not entirely understood ${ }^{(46)}$. Studies on animal models showed that a higher dietary ratio of $n-6: n-3$ PUFA increases the expression of several genes (apoA1, ABCA1) involved in the metabolism of HDL-C and cholesterol reverse transport ${ }^{(47)}$. The influence of PUFA in modulating the effect of $a p o A 1$ polymorphism and on HDL-C concentrations was also observed in the Framingham Offspring Study ${ }^{(48)}$. This might explain the possible effect of PUFA dietary intake on the expression of genes involved in cholesterol metabolism.

\section{Conclusions}

High MetS prevalence was observed in an elderly Croatian population. Consumption of poor-quality carbohydrates and meat has increased in the Mediterranean area, especially in the urban area, and thus the prevalence of MetS was similar in the Mediterranean area to that in the continental area. The difference in lifestyle habits between the rural and urban centres might be responsible for the significantly lower MetS frequency in rural centres. The nutritional habits of the participants in our multicentre study confirmed that wine and pelagic fish might have a protective effect against MetS. The number of people with MetS is increasing and the consequence is a global epidemic of obesity and diabetes, as well as high risk of CVD and liver injury.

\section{Acknowledgements}

Sources of funding: The work was supported by Project Grants 022-0222411-2407, 277-2770966-0965, 108-10803160298 and 022-0222411-2408 of the Croatian Ministry of Science, Education and Sport. Conflict of interest declaration: There are no conflicts of interest. Authorship responsibilities: The study was designed by M.P. D.P. and M.P. wrote the manuscript. M.P. and N.Č. were responsible for the medical check-ups and D.P., S.D. and J.J. for the biochemical analyses. D.P. and A.P. supervised the statistical analysis. D.P. was responsible for review and revision of the manuscript, with assistance from M.P. and J.J.

\section{References}

1. World Health Organization (1999) Definition, Diagnosis and Classification of Diabetes Mellitus and Its Complications. Report of a WHO Consultation. Geneva: WHO.

2. Expert Panel on Detection, Evaluation, and Treatment of High Blood Cholesterol in Adults (2001) Executive Summary of the Third Report of the National Cholesterol Education Program (NCEP) Expert Panel on Detection, Evaluation, and Treatment of High Blood Cholesterol in Adults (Adult Treatment Panel III). JAMA 285, 2486-2497.

3. Alberti KGMM, Zimmet P \& Shaw J (2006) Metabolic syndrome - a new world-wide definition. A Consensus Statement from the International Diabetes Federation. Diabet Med 23, 469-480.

4. Eckel RH, Grundy SM \& Zimmet PZ (2005) The metabolic syndrome. Lancet 365, 1415-1428.

5. Zimmet P, Alberti KG \& Shaw J (2001) Global and societal implications of the diabetes epidemic. Nature $\mathbf{4 1 4}$, 782-787.

6. Grundy SM, Hansen B, Smith SC Jr et al. (2004) Clinical management of metabolic syndrome: report of the American Heart Association/National Heart, Lung, and Blood Institute/American Diabetes Association conference on scientific issues related to management. Circulation 109, 551-556.

7. Martínez-González MA, Martínez JA, Hu FB et al. (1999) Physical inactivity, sedentary lifestyle and obesity in the European Union. Int $J$ Obes Relat Metab Disord 23, $1192-1201$.

8. Cameron AJ, Shaw JE \& Zimmet PZ (2004) The metabolic syndrome: prevalence in worldwide populations. Endocrinol Metab Clin North Am 33, 351-375.

9. Kolčić I, Vorko-Jović A, Salzer B et al. (2006) Metabolic syndrome in a metapopulation of Croatian island isolates. Croat Med J 47, 585-592.

10. Giugliano D, Ceriello A \& Esposito K (2006) The effects of diet on inflammation: emphasis on the metabolic syndrome. J Am Coll Cardiol 48, 677-685. 
11. Tortosa A, Bes-Rastrollo M, Sanchez-Villegas A et al. (2007) Mediterranean diet inversely associated with the incidence of metabolic syndrome: the SUN prospective cohort. Diabetes Care 30, 2957-2959.

12. Pavlović M \& Črović N (2009) An overview of the 1969-2007 follow-up study of chronic diseases and healthy ageing in Croatia and pertinent publications. Arh Hig Rada Toksikol 60, 61-68.

13. Pavlović M, Jazbec A, Šimić D et al. (2000) Variation in survival in coastal and continental regions of Croatia results of a longitudinal study. Eur J Epidemiol 16, 1061-1068

14. Jazbec A, Šimić D, Čorović N et al. (2003) Impact of coffee and other selected factors on general mortality and mortality due to cardiovascular disease in Croatia. $J$ Health Popul Nutr 21, 332-340.

15. Milošević M, Mustajbegović J, Abdović S et al. (2007) Relationship of regional alcohol drinking habit and cardiovascular risk factors in Croatia. Acta Med Croatica 61, 275-279.

16. Grundy SM (2008) Metabolic syndrome pandemic. Arterioscler Thromb Vasc Biol 28, 629-636.

17. Vuletić S, Kern J, Ivanković D et al. (2007) Metabolic syndrome in the Croatian population - the multiple cardiovascular risks. Acta Med Croatica 61, 239-243.

18. Rathmann W, Haastert B, Icks A et al. (2006) Prevalence of the metabolic syndrome in the elderly population according to IDF, WHO, and NCEP definitions and associations with C-reactive protein: the KORA Survey 2000. Diabetes Care 29, 461.

19. Athyros VG, Bouloukos VI, Pehlivanidis AN et al; MetSGreece Collaborative Group (2005) The prevalence of the metabolic syndrome in Greece: the MetS-Greece Multicentre Study. Diabetes Obes Metab 7, 397-405.

20. Bergovec M, Reiner Z, Miličić D et al. (2008) Differences in risk factors for coronary heart disease in patients from continental and Mediterranean regions of Croatia. Wien Klin Wochenschr 120, 684-692.

21. Reiner Z, Mihatov S, Miličić D et al.; TASPIC-CRO Study Group Investigators (2006) Treatment and secondary prevention of ischemic coronary events in Croatia (TASPIC-CRO study). Eur J Cardiovasc Prev Rehabil 13, 646-654.

22. Knoops KT, de Groot LC, Kromhout D et al. (2004) Mediterranean diet, lifestyle factors, and 10-year mortality in elderly European men and women: the HALE project. JAMA 292, 1433-1439.

23. Astrup A, Dyerberg J, Selleck M et al. (2008) Nutrition transition and its relationship to the development of obesity and related chronic diseases. Obes Rev 9, Suppl. 1, S48-S52.

24. Esposito K, Ciotola M \& Giugliano D (2007) Mediterranean diet and the metabolic syndrome. Mol Nutr Food Res $\mathbf{5 1}$, 1268-1274

25. Belahsen R \& Rguibi M (2006) Population health and Mediterranean diet in southern Mediterranean countries. Public Health Nutr 9, 1130-1135.

26. Thanopoulou A, Karamanos B, Angelico F et al. (2006) Epidemiological evidence for the non-random clustering of the components of the metabolic syndrome: multicentre study of the Mediterranean Group for the Study of Diabetes. Eur J Clin Nutr 60, 1376-1383.

27. Deka R, Narančić NS, Xip H et al. (2008) Metabolic syndrome in an island population of the eastern Adriatic coast of Croatia. Coll Antropol 32, 85-91.

28. Ramírez-Vargas E, Arnaud-Viñas Mdel R \& Delisle H (2007) Prevalence of the metabolic syndrome and associated lifestyles in adult males from Oaxaca, Mexico. Salud Publica Mex 49, 94-102.

29. Weng X, Liu Y, Ma J et al. (2007) An urban-rural comparison of the prevalence of the metabolic syndrome in eastern China. Public Health Nutr 10, 131-136.

30. Abdul-Rahim HF, Holmboe-Ottesen G, Stene LC et al. (2003) Obesity in a rural and an urban Palestinian West Bank population. Int J Obes Relat Metab Disord 27, 140-146.

31. Athyros VG, Liberopoulos EN, Mikhailidis DP et al. (2008) Association of drinking pattern and alcohol beverage type with the prevalence of metabolic syndrome, diabetes, coronary heart disease, stroke, and peripheral arterial disease in a Mediterranean cohort. Angiology 58, 689-697.

32. Lakka TA \& Laaksonen DE (2007) Physical activity in prevention and treatment of the metabolic syndrome. Appl Physiol Nutr Metab 32, 76-88.

33. Capizzi JA, Allen GJ, Murphy D et al. (2010) The interactive effects of metabolic syndrome, blood pressure, and mental health in worksite employees. Phys Sportsmed 38, 45-53.

34. Gigleux I, Gagnon J, St-Pierre A et al. (2006) Moderate alcohol consumption is more cardioprotective in men with the metabolic syndrome. J Nutr 136, 3027-3032.

35. Goude D, Fagerberg G \& Hulthe J (2002) Alcohol consumption, the metabolic syndrome and insulin resistance in 58-year-old clinically healthy men. Clin Sci 102, 345-352.

36. Jelski W \& Szmitkowski M (2007) Effect of ethanol on metabolic syndrome. Pol Arch Med Wewn 117, 306-311.

37. Leighton F, Miranda-Rottmann S \& Urquiaga I (2006) A central role of eNOS in the protective effect of wine against metabolic syndrome. Cell Biochem Funct 24, 291-298.

38. Marchesini G, Brizi M, Bianchi G et al. (2001) Nonalcoholic fatty liver disease: a feature of the metabolic syndrome. Diabetes 50, 1844-1850.

39. Marchesini G, Bugianesi E, Forlani G et al. (2003) Nonalcoholic fatty liver, steatohepatitis, and the metabolic syndrome. Hepatology 37, 917-923.

40. Hanley AJ, Williams K, Festa A et al. (2005) Liver markers and development of the metabolic syndrome: the insulin resistance atherosclerosis study. Diabetes 54, 3140-3147.

41. Niemelä O (2007) Biomarkers in alcoholism. Clin Chim Acta 377, 39-49.

42. Puukka K, Hietala J, Koivisto H et al. (2006) Additive effects of moderate drinking and obesity on serum $\gamma$-glutamyl transferase activity. Am J Clin Nutr 83, 1351-1354.

43. Barouki R, Chobert MN, Finidori J et al. (1983) Ethanol effects in a rat hepatoma cell line: induction of $\gamma$-glutamyltransferase. Hepatology 3, 323-329.

44. Connor WE, DeFrancesco CA \& Connor SL (1993) n-3 Fatty acids from fish oil. Effects on plasma lipoproteins and hypertriglyceridemic patients. Ann NY Acad Sci 683, $16-34$.

45. Zuliani G, Galvani M, Leitersdorf E et al. (2009) The role of polyunsaturated fatty acids (PUFA) in the treatment of dyslipidemias. Curr Pharm Des 15, 4087-4093.

46. Bitzur R, Cohen H, Kamari Y et al. (2009) Triglycerides and HDL cholesterol: stars or second leads in diabetes? Diabetes Care 32, Suppl. 2, S373-S377.

47. Zhang L, Geng Y, Xiao N et al. (2009) High dietary $n-6 / n-3$ PUFA ratio promotes HDL cholesterol level, but does not suppress atherogenesis in apolipoprotein E-null mice 1. $J$ Atheroscler Thromb 16, 463-471.

48. Ordovas JM, Corella D, Cupples LA et al. (2002) Polyunsaturated fatty acids modulate the effects of the APOA1 G-A polymorphism on HDL-cholesterol concentrations in a sex-specific manner: the Framingham Study. $A m J$ Clin Nutr 75, 38-46. 